\title{
PENGUKURAN TINGKAT KEPENTINGAN DAN PELAKSANAAN SARANA WISATA BAGI WISATAWAN MELALUI METODE IMPORTANCE PERFORMANCE ANALYSIS (IPA) DI PUSAT KONSERVASI PANTAI PENYU PARIAMAN
}

\author{
Afrinaldi M, Ira Meirina Chair, Pasaribu \\ Progam Studi D4 Manajemen Perhotelan \\ Jurusan Pariwisata \\ Fakultas Pariwisata dan Perhotelan Universitas Negeri Padang \\ e-mail: afrinaldi.andesbar@gmail.com
}

\begin{abstract}
The purpose of research is to determine the level of importance and the implementation of tourist facilities for tourists through the method of Importance Performance Analysis (IPA) in Pusat Konservasi Pantai Penyu in Pariaman city. This research consists of 3 indicators of tourism facilities, namely: basic tourism facilities, complementary tourism facilities, tourism support facilities. The type of this research is quantitative descriptive research with survey method. The population in this study are all tourists who visit Pusat Konservasi Pantai Penyu with large population and the number is not known for sure. Sampling technique is non probability sampling, by using purposive sampling. The number of samples in this study amounted to 81 tourists. Data collection using questionnaires based on Likert Scale that has been tested for its validity and reliability. Based on the research result, it is concluded that in general the level of importance and the implementation of tourism facilities for tourists through the method of Importance Performance Analysis of $40 \%$ of tourists stated that tourism is important and needs to be provided and maintained in the restaurants, daily market, souvenir shop and mushalla.
\end{abstract}

Keywords: Level of Interest, Implementation, Importance Performance Analysis, Pusat Konservasi Pantai Penyu

\section{PENDAHULUAN}

Sarana wisata sangat penting

untuk pengembangan suatu objek wisata sebab menurut Suwantoro (2004:22) menjelaskan "sarana wisata merupakan kelengkapan daerah tujuan wisata yang diperlukan untuk melayani kebutuhan wisatawan dalam menikmati perjalanan wisatanya seperti : hotel, biro perjalanan, alat transportasi, restoran dan rumah makan". Menurut Suwantoro (2004:22) sarana pariwisata terbagi atas sarana pokok kepariwisataan, sarana pelengkap kepariwisataan, sarana penunjang kepariwisataan.

Penulis melakukan observasi pada tangal 22 Januari 2018 untuk melihat dan mengetahui keadaan Pusat Konservasi Pantai Penyu Pariaman tersebut. Setelah dilakukan wawancara terhadap 10 wisatawan yang berkunjung ke Pusat Konservasi Pantai Penyu Pariaman sebanyak 50\% wisatawan menyatakan tidak puas dengan keadaan toilet di objek wisata tersebut dikarenakan toilet tersebut kurang terjaga kebersihannya serta toilet seringkali dalam keadaan terkunci sehingga tidak dapat 


\section{jox

digunakan oleh pengunjung. Sebanyak $60 \%$ wisatawan menyatakan tidak puas terhadap lahan parkir khusus yg ada di objek wisata ini, karena objek wisata ini tidak mempunyai lahan parkir khusus buat kendaraan, sebanyak 50\% wisatawan menyatakan tidak puas terhadap mushalla di Pusat Konservasi Pantai Penyu Pariaman karena mushalla yang ada hanya ada satu dan terlatak jauh di sudut pantai penyu tersebut.

Tujuan dari penelitian ini adalah untuk mengukur tingkat kepentingan sarana wisata bagi wisatawan di Pusat Konservasi Pantai Penyu Pariaman ditinjau dari sarana pokok wisata, sarana pelengkap wisata, sarana penunjang wisata. Menggunakan metode Importance Performance Analysis (IPA).

\section{METODE}

Jenis penelitian ini adalah penelitian deskriptif kuantitatif dengan metode survei. Populasi penelitian ini adalah semua wisatawan yang berkunjung ke Pusat Konservasi Pantai Penyu Pariaman dengan jumlah sampel 81 orang. Teknik pengambilan sampel adalah non probability sampling, dengan mengunakan insidental sampling.

Jenis data dalam penelitian ini adalah data primer. Data primer tersebut adalah data tentang sarana wisata yang terdapat di Pusat Konservasi Pantai Penyu. Teknik pengolahan dan analisis data yang digunakan adalah teknik dengan metode Importance Performance Analysis (IPA) atau analisis tingkat kepentingan dan kinerja.

\section{Tingkat kesesuian}

Tingkat kesesuaian adalah hasil perbandingan skor kinerja/pelaksanaa dengan skor kepentingan. Adapun rumusnya sebagai berikut:

$$
T k i=\frac{X i}{Y i} 100 \%
$$

Keterangan : Tki $=$ tingkat kesesuaian responden.

$\mathrm{Xi}=$ Skor penilaian kinerja perusahaan

$\mathrm{Yi}=$ Skor penilaian Kepentingan Sarana.

\section{Diagram Kartesius}

Diagram karteus merupakan suatu bangunan yang dibagi empat bagian dan dibatasi oleh dua garis yang berpotongan tegak lurus pada titik-titik $(\bar{Y}, \bar{Y})$, dimana $\bar{X}$ merupakan rata-rata dari rata-rata skor tingkat pelaksanaan/kinerja pengelola seluruh atribut dan $\bar{Y}$ adalah rata-rata dari rata-rata skor tingkat kepentingan seluruh atribut. Rumus yang digunakan adalah:

$$
\begin{gathered}
\bar{X}=\frac{\sum_{i=1}^{N} X 1}{K} \\
\bar{Y}=\frac{\sum_{i=1}^{N} Y 1}{K}
\end{gathered}
$$

Dimana $\mathrm{K}=$ banyaknya atribut atau fakta yang dapat mempengaruhi kepuasaan/konsumen.

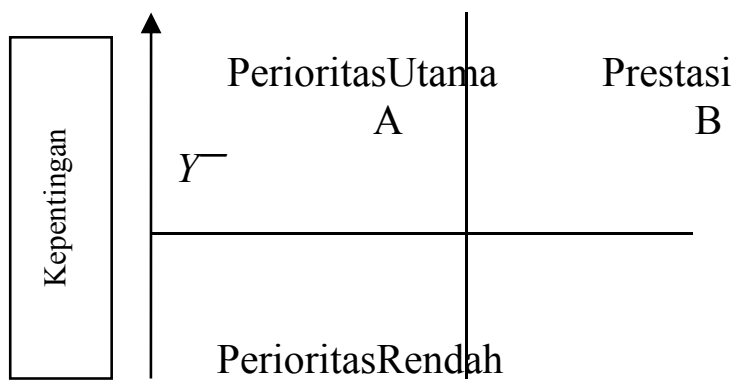

$$
\begin{array}{ll}
\stackrel{Y^{-}}{\text {berlebihan }} \\
X^{-} & \mathrm{C} \\
& \\
& \\
& \text { Pelaksanaan /Kinerja }
\end{array}
$$

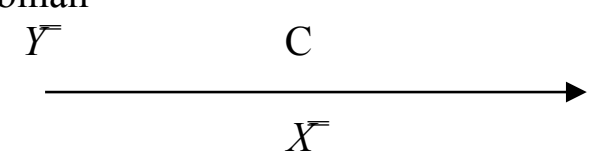

Gambar 1. Diagram Kartesius

\section{HASIL DAN PEMBAHASAN}

Pada penelitian ini, tingkat kinerja/pelaksanaan diberi kode $(\mathrm{X})$ dan tingkat kepentingan diberi kode (Y) untuk memudahkan penelitian tingkat kesesuaian diperoleh dari bobot nilai tingkat kinerja/pelaksanaan dibagi 
nilai bobot tingkat kepentingan masing-masing atribut dikali 100\%. Hasil perhitungan dapat dilihat pada table 1 dibawah ini:

\section{HASIL}

Tabel 1. Perhitungan Tingkat kesesuaian Atribut Sarana Wisata

\begin{tabular}{|c|c|c|c|c|}
\hline $\begin{array}{l}\mathbf{N} \\
\mathbf{O}\end{array}$ & $\begin{array}{c}\text { Pernyataa } \\
\text { n }\end{array}$ & $\begin{array}{l}\text { Penilai } \\
\text { an } \\
\text { Pelaks } \\
\text { anaan } \\
\text { (X) }\end{array}$ & $\begin{array}{c}\text { Pen } \\
\text { ilai } \\
\text { an } \\
\text { Ke } \\
\text { pen } \\
\text { tin } \\
\text { gan } \\
(Y) \\
\end{array}$ & Tki \\
\hline A1 & $\begin{array}{l}\text { Ketersedia } \\
\text { an travel } \\
\text { agent di } \\
\text { Pusat } \\
\text { Konservas } \\
\text { i Pantai } \\
\text { Penyu } \\
\text { (A1) }\end{array}$ & 164 & 178 & 92,13 \\
\hline A2 & $\begin{array}{l}\text { Ketersedia } \\
\text { an hotel } \\
\text { dan } \\
\text { akomodasi } \\
\text { lainya di } \\
\text { Pusat } \\
\text { Konservas } \\
\text { i Pantai } \\
\text { Penyu } \\
\text { (A2) }\end{array}$ & 171 & 215 & 79,53 \\
\hline A3 & $\begin{array}{l}\text { Ketersedia } \\
\text { an rumah } \\
\text { makan di } \\
\text { Pusat } \\
\text { Konservas } \\
\text { i Pantai } \\
\text { Penyu } \\
\text { (A3) }\end{array}$ & 215 & 209 & $\begin{array}{c}102,8 \\
7\end{array}$ \\
\hline A4 & $\begin{array}{l}\text { Ketersedia } \\
\text { an atraksi } \\
\text { wisata } \\
\text { seperti } \\
\text { surfing di }\end{array}$ & 140 & 219 & 63,92 \\
\hline
\end{tabular}

\begin{tabular}{|c|c|c|c|c|}
\hline & $\begin{array}{l}\text { Pusat } \\
\text { Konservas } \\
\text { i Pantai } \\
\text { Penyu } \\
\text { (A4) }\end{array}$ & & & \\
\hline A5 & $\begin{array}{l}\text { Ketersedia } \\
\text { an bus } \\
\text { khusus } \\
\text { wisatawan } \\
\text { di Pusat } \\
\text { Konservas } \\
\text { i Pantai } \\
\text { Penyu } \\
\text { (A5) }\end{array}$ & 175 & 208 & 84,13 \\
\hline A6 & $\begin{array}{l}\text { Ketersedia } \\
\text { an toko } \\
\text { pakaian di } \\
\text { Pusat } \\
\text { Konservas } \\
\text { i Pantai } \\
\text { Penyu } \\
\text { (A6) }\end{array}$ & 153 & 162 & 94,44 \\
\hline A7 & $\begin{array}{l}\text { Ketersedia } \\
\text { an toko } \\
\text { kebutuhan } \\
\text { harian di } \\
\text { Pusat } \\
\text { Konservas } \\
\text { i Pantai } \\
\text { Penyu } \\
\text { (A7) }\end{array}$ & 179 & 200 & 89,5 \\
\hline A8 & $\begin{array}{l}\text { Ketersedia } \\
\text { an toko } \\
\text { souvenir } \\
\text { di Pusat } \\
\text { Konservas } \\
\text { i Pantai } \\
\text { Penyu } \\
\text { (A8) }\end{array}$ & 204 & 208 & 98,07 \\
\hline A9 & $\begin{array}{l}\text { Ketersedia } \\
\text { an toilet di } \\
\text { Pusat } \\
\text { Konservas } \\
\text { i Pantai } \\
\text { Penyu } \\
\text { (A9) }\end{array}$ & 175 & 209 & 83,73 \\
\hline
\end{tabular}




\begin{tabular}{|l|l|l|l|l|}
\hline A1 & Ketersedia & & & \\
0 & an & & & \\
& mushalla & & & \\
& di Pusat & 186 & 230 & 80,86 \\
& $\begin{array}{l}\text { Konservas } \\
\text { i Pantai }\end{array}$ & & & \\
& $\begin{array}{l}\text { Penyu } \\
\text { (A10) }\end{array}$ & & & \\
\hline
\end{tabular}

Setelah diperoleh tingkat kesesuaian, maka langkah selanjutnya adalah mencari rata- rata setiap atribut sarana wisata, dengan membagi bobot penilaian tingkat kinerja/pelaksanaan dan tingkat kepentingan masing-masing dengan jumlah responden 81 orang. Selanjutnya akan diperoleh rata-rata dari rata-rata kepentingan dan tingkat kinerja/pelaksanaan dari atribut sarana wisata. Hasil perhitungan, dapat dilihat pada table 2 dibawah ini :

Table 2. Perhitungan Rata-Rata Tingkat Kinerja/Pelaksanaan Dan Tingkat Kepentingan Atribut Sarana Wisata

\begin{tabular}{|l|l|l|l|l|l|}
\hline No & $\begin{array}{l}\text { Pernya } \\
\text { taan }\end{array}$ & $\mathbf{X}$ & $\mathbf{Y}$ & $\bar{X}$ & $\overline{\mathbf{Y}}$ \\
\hline 1 & $\begin{array}{l}\text { Keterse } \\
\text { diaan } \\
\text { travel } \\
\text { agent di } \\
\text { Pusat } \\
\text { Konser } \\
\text { vasi } \\
\text { Pantai } \\
\text { Penyu }\end{array}$ & 164 & 17 & 2,0 & 2,19 \\
\hline 2 & $\begin{array}{l}\text { Keterse } \\
\text { diaan } \\
\text { hotel } \\
\text { dan } \\
\text { akomod } \\
\text { asi } \\
\text { lainya } \\
\text { di Pusat } \\
\text { Konser }\end{array}$ & 171 & 21 & 2,1 & 2,65 \\
\hline
\end{tabular}

\begin{tabular}{|c|c|c|c|c|c|}
\hline & $\begin{array}{l}\text { vasi } \\
\text { Pantai } \\
\text { Penyu }\end{array}$ & & & & \\
\hline 3 & $\begin{array}{l}\text { Keterse } \\
\text { diaan } \\
\text { rumah } \\
\text { makan } \\
\text { di Pusat } \\
\text { Konser } \\
\text { vasi } \\
\text { Pantai } \\
\text { Penyu }\end{array}$ & 215 & $\begin{array}{c}20 \\
9\end{array}$ & $\begin{array}{c}2,6 \\
5\end{array}$ & 2,58 \\
\hline 4 & $\begin{array}{l}\text { Keterse } \\
\text { diaan } \\
\text { atraksi } \\
\text { wisatas } \\
\text { eperti } \\
\text { surfing } \\
\text { di Pusat } \\
\text { Konser } \\
\text { vasi } \\
\text { Pantai } \\
\text { Penyu }\end{array}$ & 140 & $\begin{array}{c}21 \\
9\end{array}$ & $\begin{array}{c}1,7 \\
2\end{array}$ & 2,70 \\
\hline 5 & $\begin{array}{l}\text { Keterse } \\
\text { diaan } \\
\text { bus } \\
\text { khusus } \\
\text { wisata } \\
\text { wan di } \\
\text { Pusat } \\
\text { Konser } \\
\text { vasi } \\
\text { Pantai } \\
\text { Penyu }\end{array}$ & 175 & $\begin{array}{c}20 \\
8\end{array}$ & $\begin{array}{c}2,1 \\
6\end{array}$ & 2,56 \\
\hline 6 & $\begin{array}{l}\text { Keterse } \\
\text { diaan } \\
\text { toko } \\
\text { pakaian } \\
\text { di Pusat } \\
\text { Konser } \\
\text { vasi }\end{array}$ & 153 & $\begin{array}{c}16 \\
2\end{array}$ & $\begin{array}{c}1,8 \\
8\end{array}$ & 2 \\
\hline
\end{tabular}




\begin{tabular}{|c|c|c|c|c|c|}
\hline & $\begin{array}{l}\text { Pantai } \\
\text { Penyu }\end{array}$ & & & & \\
\hline 7 & $\begin{array}{l}\text { Keterse } \\
\text { diaan } \\
\text { toko } \\
\text { kebutuh } \\
\text { an } \\
\text { harian } \\
\text { di Pusat } \\
\text { Konser } \\
\text { vasi } \\
\text { Pantai } \\
\text { Penyu }\end{array}$ & 179 & $\begin{array}{c}20 \\
0\end{array}$ & $\begin{array}{c}2,2 \\
0\end{array}$ & 2,46 \\
\hline 8 & $\begin{array}{l}\text { Keterse } \\
\text { diaan } \\
\text { toko } \\
\text { souveni } \\
\text { r di } \\
\text { Pusat } \\
\text { Konser } \\
\text { vasi } \\
\text { Pantai } \\
\text { Penyu }\end{array}$ & 204 & $\begin{array}{c}20 \\
8\end{array}$ & $\begin{array}{c}2,5 \\
1\end{array}$ & 2,56 \\
\hline 9 & $\begin{array}{l}\text { Keterse } \\
\text { diaan } \\
\text { toilet di } \\
\text { Pusat } \\
\text { Konser } \\
\text { vasi } \\
\text { Pantai } \\
\text { Penyu }\end{array}$ & 175 & $\begin{array}{c}20 \\
9\end{array}$ & $\begin{array}{c}2,1 \\
6\end{array}$ & 2,58 \\
\hline 10 & $\begin{array}{l}\text { Keterse } \\
\text { diaan } \\
\text { mushall } \\
\text { a di } \\
\text { Pusat } \\
\text { Konser } \\
\text { vasi } \\
\text { Pantai } \\
\text { Penyu }\end{array}$ & 186 & $\begin{array}{c}23 \\
0\end{array}$ & $\begin{array}{c}2,2 \\
9\end{array}$ & 2,83 \\
\hline
\end{tabular}

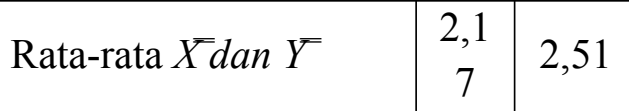

\section{Diagram Kartesius}

Pada diagram kartesius ini, akan dilakukan penempatan posisi atribut sarana wisata berdasarkan Importance Performance Analysis Matrix, yang dapat dilihat pada gambar 1 di bawah ini:

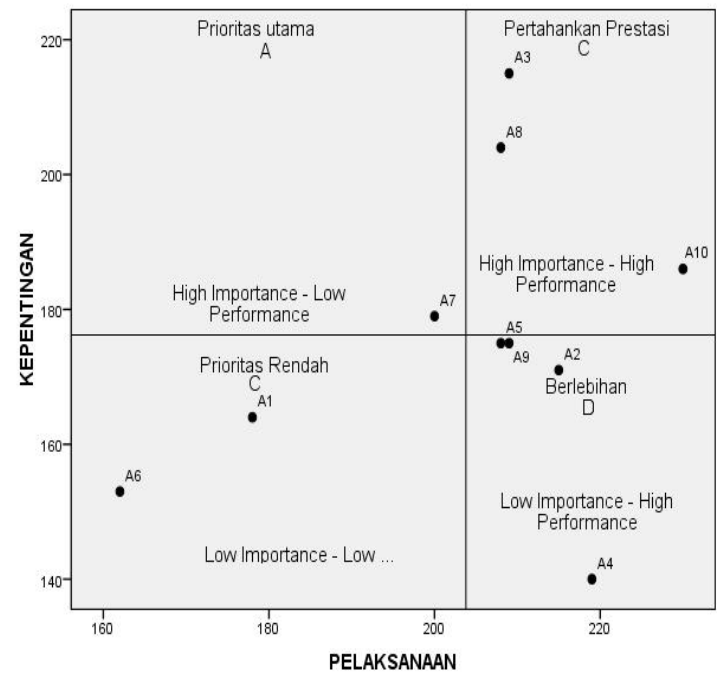

Ga

mbar 2. Hasil Diagram Kartesius Sarana Wisata.

Berdasarkan penempatan atribut sarana wisata di atas, maka diperoleh tingkat kepentingan sarana wisata untuk masing-masing dimensi sarana wisata yaitu:

a. Sarana pokok wisata

Indikator ini dikelompokan jadi empat atribut yaitu:

1) Ketersediaan travel agent di Pusat Konservasi Pantai Penyu (Kuadran C, Kurang Penting)

2) Ketersediaan hotel dan akomodasi lainnya di Pusat Konservasi Pantai Penyu (Kuadran D, Kurang Penting)

3) Ketersediaan rumah makan di Pusat Konservasi Pantai Penyu (Kuadran B, Sangat Penting) 


\section{Jnk

4) Ketersediaan atraksi wisata di Pusat Konservasi Pantai Penyu ( Kuadran D, Kurang Penting )

Berdasarkan uraian diatas diperoleh tingkat kepentingan sarana wisata bagi pengunjung di Pusat Konservasi Pantai Penyu Pariaman dari indikator sarana pokok wisata yaitu: sangat penting $=1 / 4 \times 100 \%=$ $25 \%$, kurang penting $=3 / 4 \times 100 \%=75 \%$.

b. Sarana pelengkap wisata

Dimensi ini terdiri dari empat atribut yaitu:

1) Ketersediaan bus khusus wisatawan di Pusat Konservasi Pantai Penyu (Kuadran D, Kurang Penting)

2) Ketersediaan toko pakaian di Pusat Konservasi Pantai Penyu (Kuadran C, Kurang Penting)

3) Ketersediaan toko kebutuhan harian di Pusat Konservasi Pantai Penyu (Kuadran

\section{A, Sangat Penting)}

Berdasarkan uraian diatas diperoleh tingkat kepentingan sarana wisata bagi pengunjung di Pusat Konservasi Pantai Penyu Pariaman dari indikator sarana pelengkap wisata yaitu: kurang penting $=2 / 3$ $\mathrm{x} 100 \%=66,6 \%$, sangat Penting $=1 / 3 \quad \mathrm{x}$ $100 \%=33,3 \%$

c. Sarana penunjang wisata

Dimensi ini terdiri dari tiga dimensi yaitu:

1) Ketersediaan toko souvenir di Pusat Konservasi Pantai Penyu (Kuadran B, Sangat Penting)

2) Ketersediaan toilet di Pusat Konservasi Pantai Penyu (Kuadran D, Kurang Penting)

3) Ketersediaan mushalla di Pusat Konservasi Pantai Penyu (Kuadran B, Sangat Penting)

Berdasarkan uraian diatas diperoleh tingkat kepentingan sarana wisata bagi pengunjung di Pusat Konservasi Pantai
Penyu Pariaman dari indikator sarana penunjang wisata yaitu: kurang penting $=1 / 3$ $\mathrm{x} 100 \%=33,3 \%$, sangat penting $=2 / 3 \mathrm{x}$ $100 \%=66,6 \%$

Setelah diperoleh tingkat kepentingan sarana wisata bagi pengunjung dari masingmasing indikator sarana wisata, diperoleh tingkat kepentingan sarana wisata bagi pengunjung secara umum sebanyak 4/10 x $100 \%=40 \%$ wisatawan menyatakan sarana wisata sangat penting, $6 / 10 \times 100 \%=60 \%$ wisatawan menyatakan sarana wisata kurang penting.

\section{PEMBAHASAN}

Penelitian ini telah mengukur dan menganalisa tingkat kepentingan sarana wisata bagi wisatawan di Pusat Konservasi Pantai Penyu Kota Pariaman terdiri dari 3 indikator. Penelitian ini menggunakan metode Importance Performance Analysis (IPA).

Adapun interprestasi tingkat kepentingan sarana wisata bagi pengunjung dari diagram kartesius tersebut dapat dijelaskan sebagai berikut:

\section{Sarana pokok wisata}

Adapun atribut sarana pokok wisata dari sub indikator yang telah dikelompokan dalam diagram kartesius yaitu:

Ketersediaan travel agent di Pusat Konservasi Pantai Penyu Pariaman (Kuadran C) merupakan atribut yang dianggap kurang penting bagi wisatawan. Oleh karena itu pihak pegelola tidak perlu menyediakan travel agent.

Ketersediaan hotel dan akomodasi lainnya di Pusat Konservasi Pantai Penyu Pariaman (Kuadran D) merupakan atribut yang dianggap kurang penting bagi wisatawan. Oleh karena itu pihak pengelola sebaiknya mengembangkan sarana wisata lain yang lebih dibutuhkan.

Ketersediaan rumah makan di Pusat Konservasi Pantai Penyu Pariaman (Kuadran B) 


\section{Jnk

merupakan atribut yang dianggap sangat penting oleh wisatawan. Maka dari itu pengelola perlu menyediakan rumah makan dan apabila sudah tersedia maka harus dipertahankan. Ketersediaan atraksi wisata di Pusat Konservasi Pantai Penyu Pariaman (Kuadran D) merupakan atribut yang dianggap kurang penting bagi wisatawan. Oleh karena itu pihak pengelola tidak perlu menambahkan atraksi wisata .

Menurut Yoeti (2009:199) "Sarana pokok wisata adalah perusahaan yang hidup dan kehidupannya sangat tergantung kepada arus kedatangan orang yang melakukan perjalanan wisata". Fungsinya adalah menyediakan fasilitas pokok yang dapat memenuhi kebutuhan wisatawan".

2. Sarana pelengkap wisata

Adapun atribut sarana pelengkap wisata dari sub indikator yang telah dikelompokan dalam diagram kartesius yaitu:

Ketersediaan bus khusus wisatawan di Pusat Konservasi Pantai Penyu Pariaman (Kuadran D) merupakan atribut yang di anggap kurang penting bagi wisatawan. Sehingga pengelola tidak perlu menyediakan bus khusus wisatawan. Ketersediaan toko pakaian di Pusat Konservasi Pantai Penyu Pariaman (Kuadran C) merupakan atribut yang di anggap kurang penting bagi wisatawan. Sehingga pengelola tidak perlu menyediakan toko pakaian.

Ketersediaan toko kebutuhan harian di Pusat Konservasi Pantai Penyu Pariaman (Kuadran A) merupakan atribut yang di anggap sangat penting bagi wisatawan. Oleh karena itu pengelola perlu menyediakan toko kebutuhan harian.

Menurut Yoeti (2009:201) "Sarana pelengkap wisata yaitu tempat-tempat yang menyediakan fasilitas untuk rekreasi yang dapat melengkapi sarana pokok fungsinya dapat membuat wisatawan lebih lama tinggal di tempat atau daerah yang dikunjunginya".

3. Sarana penunjang wisata

Adapun atribut sarana penunjang wisata dari sub indikator yang telah dikelompokan dalam diagram kartesius yaitu:

Ketersediaan toko souvenir di Pusat Konservasi Pantai Penyu Pariaman (Kuadran B) merupakan atribut yang di anggap sangat penting bagi wisatawan. Oleh karena itu pengelola perlu menyediakan toko souvenir.

Ketersediaan toilet di Pusat Konservasi Pantai Penyu Pariaman (Kuadran D) merupakan atribut yang dianggap wisatawan kurang penting. Sehingga pihak pengelola tidak perlu menyediakan toilet dan apabila sudah ada perlu dipertahankan.

Ketersediaan mushalla di Pusat Konservasi Pantai Penyu Pariaman (Kuadran B) merupakan atribut yang dianggap wisatawan sangat penting. Oleh karena itu pihak pengelola perlu menyediakan mushalla dan apabila sudah ada perlu dipertahankan.

Menurut Yoeti (2009: 203) Sarana penunjang wisata adalah perusahaan yang menunjang sarana pelengkap dan sarana pokok dan berfungsi tidak hanya membuat wisatawan lebih lama tinggal pada suatu daerah tujuan wisata, tetapi fungsi yang lebih penting adalah agar wisatawan lebih banyak mengeluarkan atau membelanjakan uangnya di tempat yang dikunjungi.

Setelah diperoleh tingkat kepentingan sarana wisata bagi pengunjung dengan metode Importance Performance Analysis (IPA), 40\% wisatawan menyatakan sarana wisata sangat penting yang berada di kuadran A dan kuadran B berupa rumah makan, toko kebutuhan harian, toko souvenir, dan musholla, Menurut Yoeti (2009:199) yang termasuk sarana pokok wisata yaitu "rumah makan". Sedangkan Menurut 


\section{Jnk

Yoeti (2009:201) yang termasuk sarana pelengkap adalah " toko kebutuhan harian". Sedangkan menurut Yoeti (2009 : 202) yang termasuk sarana penunjang wisata adalah " Musholla,dan lain-lain" Oleh sebab itu pihak pengelola perlu menyediakan sarana wisata yang di anggap penting oleh wisatawan agar Pusat Konservasi Pantai Penyu bisa lebih berkembang dan kebutuhan wisatawan yang datang ke Pusat Konservasi Pantai Penyu bisa terpenuhi sehingga akan membuat wisatawan puas saat berkunjung ke objek wisata ini

\section{PENUTUP}

\section{Simpulan}

Berdasarkan uraian dan hasil pengukuran tingkat kepentingan sarana dan pelaksanaan wisata bagi pengunjung dengan menggunakan metode Importance Performance Analysis (IPA) yang telah dikemukakan diatas, dapat disimpulkan secara umum, sebanyak 40\% wisatawan menyatakan sarana wisata sangat penting di Pusat Konservasi Pantai Penyu Pariaman. Untuk lebih jelasnya dapat diuraiakan sebagai berikut:

Tingkat kepentingan sarana wisata ditinjau dari indikator sarana pokok wisata yaitu: sebanyak $75 \%$ wisatawan menyatakan sarana pokok wisata berupa travel agent, hotel dan akomodasi lainnya dan atraksi wisata merupakan sarana wisata yang kurang penting dan $25 \%$ lainnya menyatakan sarana pokok wisata rumah makan sangat penting dan perlu disediakan agar kepuasan wisatawan saat berkunjung ke Pusat Konservasi Pantai Penyu tercapai.

Tingkat kepentingan sarana wisata ditinjau dari sarana pelengkap wisata yaitu 33,3\% wisatawan menyatakan sarana pelengkap wisata seperti toko kebutuhan harian merupakan sarana wisata yang sangat penting dan perlu disediakan agar kepuasan wisatawan saat berkunjung ke pusat konservasi dapat terpenuhi.

Tingkat kepentingan sarana wisata ditinjau dari indikator sarana penunjang wisata yaitu: sebanyak 66\% wisatawan menyatakan sarana penunjang wisata berupa souvenir dan mushala merupakan sarana wisata yang sangat penting dan perlu disediakan.

\section{Saran}

Setelah dilakukakan penelitian, diusulkan kepada Dinas Pariwisata dan Kebudayaan, hendaknya menyediakan dan menjaga atribut sarana wisata yang menjadi perioritas utama oleh wisatawan yaitu rumah makan, dan sarana wisata yang patut dipertahankan yaitu toko kebutuhan harian, toko souvenir dan mushollla.

Disarankan agar penelitian ini menjadi bahan untuk menambah wawasan dan ilmu pengetahuan untuk mengukur tingkat kepentingan dengan metode Importance Performance Anlysis (IPA) jika memungkinkan objek wisata ini bisa dijadikan tempat pengabdian masyarakat oleh dosen-dosen jurusan Pariwisata Fakultas Pariwisata dan Perhotelan.

Kepada peneliti lain yang ingin melakukan penelitian lebih lanjut sebaiknya ditambahkan variable-variabel lain yang relevan dengan penelitian seperti sapta pesona, destinasi wisata, daya tarik wisata dengan menggunakan metode Importance Performance Analysis (IPA) serta bisa ditambahkan dengan metode lain seperti Costumer satisfaction index (CSI)

\section{DAFTAR PUSTAKA}

Suwantoro, Gamal. 2004. Dasar-Dasar Pariwisata. Yogyakarta: CV.Andi Offset.

Yoeti, Oka A. 2009. Pengantar Ilmu Pariwisata. Bandung: Angkasa. 